\title{
SYSTEMIC ANTICOAGULATION IN THE SETTING OF VASCULAR EXTREMITY TRAUMA
}

\section{SYSTEMIC ANTICOAGULATION IN THE SETTING OF VASCULAR EXTREMITY TRAUMA}

Melissa N. Loja, M.D., M.A.S.; Joseph M. Galante, M.D.; Misty Humphries, M.D.; Stephanie Savage, M.D., M.S.; Timothy Fabian, M.D.; Thomas Scalea, M.D.; John B. Holcomb, M.D.; Nathaniel Poulin, M.D.; Joseph DuBose, M.D.; Todd E. Rasmussen, M.D.; and the AAST PROOVIT Study Group

Corresponding Author: Melissa N. Loja, M.D., M.A.S. mloja@ucdavis.edu University of California, Davis Department of Surgery, Division of Vascular Surgery 4860 Y Street, Suite 3400

Sacramento, CA 95817

Phone (916) 734-2024

Fax (916) 734-2026

Joseph M. Galante, M.D.

Department of Surgery, Division of Trauma Surgery, University of California, Davis Sacramento, CA, USA jmgalante@ucdavis.edu

Misty Humphries, M.D. Department of Surgery, Division of Vascular Surgery, University of California, Davis Sacramento, CA, USA $\underline{\text { mdhumphries@ucdavis.edu }}$

Stephanie Savage, M.D., M.S.

Department of Surgery, Indiana University School of Medicine Indianapolis, IN, USA ssavage2@IUHeath.org

Timothy Fabian, M.D.

Department of Surgery, University of Tennessee

Memphis, TN, USA

tfabian@uthsc.edu

Thomas Scalea, M.D.

Department of Surgery, R Adams Cowley Shock Trauma Center, University of Maryland Baltimore, MD, USA tscalea@umm.edu

This is the author's manuscript of the article published in final edited form as: Loja, M. N., Galante, J. M., Humphries, M., Savage, S., Fabian, T., Scalea, T., ... Rasmussen, T. E. (n.d.). Systemic anticoagulation in the setting of vascular extremity trauma. Injury. https://doi.org/10.1016/j.injury.2017.03.020 
John B. Holcomb, M.D.

Department of Surgery, Center for Translational Injury Research, University of Texas Health Sciences Center Houston Houston, TX, USA

$\underline{\text { John.Holcomb@uth.tmc.edu }}$

Nathaniel Poulin, M.D.

Department of Surgery, Eastern Carolina University Medical Center

Greenville, NC, USA

nathaniel.poulin@vidanthealth.com

Joseph DuBose, M.D.

Department of Surgery, Divisions of Vascular and Trauma Surgery, University of California Davis

Sacramento, CA, USA

jjd3c@yahoo.com

Todd E. Rasmussen, M.D.

Department of Surgery, R Adams Cowley Shock Trauma Center, University of Maryland Baltimore, MD, USA

todd.e.rasmussen.mil@mail.mil

\section{and the AAST PROOVIT Study Group:}

Tiffany Bee MD; Timothy Fabian, MD

University of Tennessee Health Sciences Center-Memphis, TN, USA

Jay Menaker, MD; Megan Brenner, MD; Thomas M. Scalea, MD, Todd E. Rasmussen, MD

University of Maryland, $R$ Adams Cowley Shock Trauma Center - Baltimore, MD, USA

Jeanette M. Podbielski, RN, CCRP; John B. Holcomb, MD; Garrett Jost

University of Texas Health Sciences Center, Houston - Houston, TX, USA

David Skarupa, MD; Jennifer A. Mull, RN, CCRC; Joannis Baez Gonzalez

University of Florida, Jacksonville - Jacksonville, FL, USA

Jayun Cho, MD; Kenji Inaba, MD

Los Angeles County + University of Southern California Hospital - Los Angeles, CA, USA

Richard D. Catalano, MD; Ahmed M. Abou-Zamzam Jr, MD; Xian Luo-Owen, PhD; Ian S.H. Vannix, BS

Loma Linda University Medical Center - Loma Linda, CA, USA 
Nathaniel Poulin, MD

East Carolina Medical Center - Greenville, NC, USA

John K. Bini, MD; Karen Herzig, BSN, RN

Wright State Research Institute - Miami Valley Hospital - Dayton, OH, USA

Scott T. Trexler, MD; Sonya Charo-Griego, RN; Douglas Johnson, LVN

San Antonio Military Medical Center / US Army Institute of Surgical Research - JBSA Fort Sam Houston, TX, USA

John Myers, MD; Michael Johnson, MD; Kristin Rocchi, RN

The University of Texas Health Sciences Center at San Antonio - San Antonio, TX, USA

Stephanie A. Savage, MD, MS

Indiana University School of Medicine - Indianapolis, IN, USA

Ramyar Gilani, MD; Tikesha Smith

Ben Taub General Hospital / Baylor College of Medicine - Houston, TX, USA

George Dulabon, MD; Riyad Karmy-Jones

Peace Health Southwest Washington Medical Center - Vancouver, Washington, USA

Andreas Larentzakis MD; George Velmahos, MD

Massachusetts General Hospital - Boston, Massachusetts, USA

Melissa N. Loja, MD, MAS; Joseph Galante, MD; Misty Humphries, MD; Joseph DuBose, MD

University of California, Davis - Sacramento, CA, USA

Steven R. Shackford, MD; Michael Sise, MD

Scripps Mercy Hospital - San Diego, CA, USA

Forrest O. Moore, MD; Annette Taylor, RN, BSN, CCRC; John Michael Sherman;

Jeannette G. Ward, MS-CR

University of Arizona - Chandler Regional Medical Center - Phoenix, AZ, USA

Fausto Y. Vinces, DO; Salvatore Docimo, DO

Lutheran Medical Center - Brooklyn, New York, USA

Ramyar Gilani, MD; Reginva Knight

Ben Taub Hospital / Baylor College of Medicine - Houston, TX, USA

Matthew M. Carrick, MD; Barbara Shaffer, RN, BSN

The Medical Center of Plano - Plano, TX, USA

Jonathan P. Meizoso, MD

Ryder Trauma Center, University of Miami - Miami, FL, USA

Ravi R. Rajani, MD

Emory University School of Medicine, Grady Memorial Hospital - Atlanta, GA, USA 


\title{
Sameer Hirji, MD; Jonathan D. Gates, MD, MBA
}

Brigham and Women's Hospital - Boston, MA, USA

\begin{abstract}
Introduction: There is conflicting data regarding if patients with vascular extremity trauma who undergo surgical treatment need to be systematically anticoagulated. We hypothesized that intraoperative systemic anticoagulation (ISA) decreased the risk of repair thrombosis or limb amputation after traumatic vascular injury of the extremities.
\end{abstract}

Methods: We analyzed a composite risk of repair thrombosis and/or limb amputation (RTLA) between patients who did and did not undergo ISA during arterial injury repair. Patient data was collected in the American Association for the Surgery of Trauma PROspective Vascular Injury Treatment (PROOVIT) registry. This registry contains demographic, diagnostic, treatment, and outcome data.

Results: Between February 2013 and August 2015, 193 patients with upper or lower extremity arterial injuries who underwent open operative repair were entered into the PROOVIT registry. The majority were male (87\%) with a mean age of 32.6 years (range 4-91) and $74 \%$ injured by penetrating mechanism. $63 \%$ of the injuries were described as arterial transection and $37 \%$ had concomitant venous injury. $62 \%$ of patients underwent ISA. RTLA occurred in 22 patients (11\%) overall, with no significant difference in these outcomes between patients who received ISA and those that did not $(10 \%$ vs. $14 \%, \mathrm{p}=0.6)$. There was, however, significantly higher total blood product use noted among patients treated with ISA versus those that did not receive ISA (median 3 units vs. 1 unit, $p=0.002$ ). Patients treated with ISA also stayed longer in the ICU (median 3 days vs. 1 day, $\mathrm{p}=0.001$ ) and hospital (median 9.5 days vs. 6 days, $\mathrm{p}=0.01$ ). 
Discussion: In this multicenter prospective cohort, intraoperative systemic anticoagulation was not associated with a difference in rate of repair thrombosis or limb loss; but was associated with an increase in blood product requirements and prolonged hospital stay. Our data suggest there is no significant difference in outcome to support use of ISA for repair of traumatic arterial injuries.

Keywords: anticoagulation; trauma; vascular; extremity; amputation 


\section{BACKGROUND}

Routine intraoperative systemic anticoagulation (ISA) is a mainstay of therapy in elective arterial reconstruction and treatment of acute limb ischemia (1). In the setting of trauma, surgeons have been reluctant or unable to systemically anticoagulate patients when performing arterial repair due to concern for potential local and systemic bleeding (2). It is unclear if the improved patency seen with elective vascular repair can be generalized to traumatic arterial repair, particularly in patients with acute traumatic coagulopathy or resuscitation-associated coagulopathy. There is limited and conflicting retrospective data in the literature correlating improved patency or limb salvage with use of ISA during traumatic arterial injury repair (3-9). Retrospective reviews of patients who received ISA during lower extremity arterial injury repair report a limb salvage rate of $85-91 \%(2,5,7,8)$. Other reviews, however, report lower limb salvage rates of $83-84 \%$ with similar injuries, despite routinely not giving ISA $(4,10)$. Comparative studies have shown no statistically significant difference in outcome between patients who are given ISA and those who are not $(6,7)$. Proponents, however, argue that the risks of ISA are minimal, and may decrease the risk of distal in situ thrombus or microvascular

thrombosis $(5,9)$. We hypothesized that intraoperative systemic anticoagulation (ISA) decreased the risk of repair thrombosis or limb amputation (RTLA) after traumatic vascular injury of the extremities.

\section{METHODS}

Patient data was collected from the American Association for the Surgery of Trauma (AAST) Multicenter PROspective Observational Vascular Injury Treatment (PROOVIT) registry. The details of this registry have been previously described (11). This is a 
prospectively-collected database of injuries to named arterial and venous structures from fourteen Level I trauma centers across the United States. The database includes demographic, diagnostic, treatment, and outcome data for the index hospital stay. The registry is accruing data from clinic and readmission follow up.

Patients with upper or lower extremity arterial injuries who underwent open arterial revascularization between February 2013 and August 2015 were identified. Patients treated with arterial ligation, primary traumatic amputation, endovascular repair or embolization were excluded. Arterial injuries to the upper extremity utilized for analysis included individual injuries to the brachial or distal forearm arteries. The rare combined brachial and radial artery injuries were categorized as brachial artery injuries. Arterial injuries to the lower extremity included individual injuries to the femoral, popliteal or distal to the popliteal artery. Method of repair included autologous conduit, synthetic interposition or bypass graft and primary repair. Patients treated with vein interposition or bypass, vein patch or autologous artery as a conduit were included in the autologous category. ISA was defined as systemic anticoagulation with unfractionated heparin (UFH) utilized during the initial operation or vascular repair. Intraoperative regional anticoagulation was not included in this study. The total mangled extremity severity score (MESS) was calculated as originally described by Johansen et al., from the prospectively obtained components described in Appendix A (12).

The primary endpoint was a composite risk of RTLA during the index admission, between patients who did and did not undergo ISA during arterial injury repair. Secondary endpoints included need for reintervention after initial operation for any reason, total units of packed red blood cells (PRBC) required in the first 24 hours, length of intensive care unit (ICU) stay and length of total hospital stay. 
Statistical analysis was performed using Stata Version 14.1 (StataCorp, College Station, TX, USA). Differences in demographics for patients who received ISA and were compared using the Wilcoxon rank-sum test for ordinal variables and two-sample t-test for continuous variables. The Fisher's exact test was used for $2 \times 2$ contingency tables with 20 or less patients in any category. P-values are reported as double the 1-sided exact probability. Pearson's chisquared test with Yates' correction for continuity was used for $2 \times 2$ contingency tables when there were between 21 and 40 patients in a given category. Pearson's chi-squared test was used for all larger contingency tables. A p-value $<0.05$ was considered statistically significant.

\section{RESULTS}

Between February 2013 and August 2015, 193 patients with upper or lower extremity arterial injuries who underwent open arterial repair were entered into the PROOVIT registry from 14 Level-1 trauma centers. The 14 centers contributed between 1 and 52 patients each (mean 13.8, median 4), with five centers being the largest contributors with over 25 patients each. ISA was given to 119 patients in total $(62 \%)$. The patients were predominantly male, with a mean age of 32.6 years (range 4-91, Table 1). Men were more likely to receive ISA than women (92\% ISA were male vs. $78 \%$ without ISA were male, $\mathrm{p}=0.02)$. Most injuries were penetrating in nature (74\%), and were most often caused by gunshot wounds $(42 \%)$. The injury identified was most often a transection (63\%). There were no differences in ISS, admission systolic blood pressure, or Glasgow coma score (GCS) between patients who received ISA and those who did not. There was a trend towards higher AIS-extremity in patients who received ISA compared to those who did not, but it did not reach statistical significance (median of $3\left(25^{\text {th }}\right.$ percentile (Q1) - 75 ${ }^{\text {th }}$ percentile (Q3) 3-3) vs. $\left.3(\mathrm{Q} 1-\mathrm{Q} 32-3), \mathrm{p}=0.06\right)$. MESS did not differ 
between patients who received ISA than those who did not (median of 4 (Q1-Q3 3-6) vs. 4 (Q1Q3 3-5), $\mathrm{p}=0.08$ ). When each component was analyzed individually, however, patients who received ISA had a higher limb ischemia score compared to those who did not (median of 2 (Q1Q3 1-2) vs. 1 (Q1-Q3 1-1), p < 0.001).

In total, there were 71 concomitant venous injuries (37\%), of which 63 were repaired $(89 \%)$. The remaining 8 injured veins were ligated. Sixty-three patients had concomitant nerve injuries (33\%), and 66 patients had associated orthopedic injury (34\%). There were no significant differences in concomitant venous or orthopedic injuries between patients who received ISA and those who did not. Patients with concomitant nerve injuries were less likely to receive ISA ( $26 \%$ with ISA vs. $43 \%$ without, $\mathrm{p}=0.02)$.

Forty-three patients had a pre-hospital tourniquet placed (22\%). Most patients had an ischemia time (from time of injury to time of definitive repair) between 3 and 6 hours (54\%, Table 2). Damage-control temporary shunt placement was used in 9 patients (5\%), 8 of whom received ISA. Arterial repair with autologous conduit was performed in 103 patients (53\%), including 100 vein interposition or bypass grafts, 2 vein patches and one autologous artery used as conduit. The artery was repaired primarily in 81 patients (42\%), and with synthetic graft in 8 patients $(4 \%)$. Patients who underwent a repair with any autologous conduit were more likely to receive ISA than not $(62 \%$ vs. $39 \%, \mathrm{p}=0.001)$. Twenty-eight patients $(15 \%)$ required a revision of the arterial repair during the initial operation (Table 2). There was no difference in administration of ISA in patients who required immediate revision (17\% with ISA vs $11 \%$ without, $\mathrm{p}=0.3$ ). Extremity fasciotomies were performed in 78 patients, including 13 involving the upper extremity. Patients who underwent fasciotomy at any time during the initial hospitalization were more likely to have received ISA than not ( $48 \%$ vs. $28 \%, \mathrm{p}=0.01)$. 
Patients who had an operative time of greater than 6 hours were more likely to receive ISA than not $(10 \%$ vs. $5 \%, p=0.04)$

There were 96 and 97 injuries to the upper and lower extremity, respectively. There were no combined upper and lower extremity injuries, and no combined above- and below-knee arterial injuries. There were two combined brachial and radial injuries. ISA was given for popliteal arterial injuries in $84 \%$ (26/31) of cases, in 67\% (39/58) of femoral and in only $38 \%$ (3/8) of below-popliteal injuries ( $\mathrm{p}<0.001$, Table 3$)$. The total limb salvage rate was $94 \%$ (182/193). Popliteal artery injuries had the lowest rate of limb salvage (84\%, 26/31). Lower extremity amputations were more frequent than upper extremity amputations (10\% of lower extremity injuries (10/97) vs. $1.0 \%$ of upper $(1 / 96), \mathrm{p}=0.005)$. Rates of amputation and RTLA by artery injured and ISA status can be found in Table 3. Results were not analyzed for statistical significance given small numbers per group.

RTLA occurred in 22 patients (11\%), including 11 amputations and 13 instances of graft thrombosis (Table 4). There was no significant difference in RTLA between patients who received ISA and those that did not $(12 / 119(10 \%)$ vs. $10 / 74(14 \%), p=0.6)$.

There was significantly higher total blood product use among patients treated with ISA versus those that did not receive ISA (median 3 units (Q1-Q3 0-8) vs. 1 unit (Q1-Q3 0-4, p = 0.002). There was a longer length of ICU (median 3 days (Q1-Q3 1-6) vs. 1 day (Q1-Q3 0-3), p $=0.001)$ and hospital length of stay (median 9.5 days (Q1-Q3 4-18.5) vs. 6 days (Q1-Q3 2-13), p $=0.01)$ in patients treated with ISA compared to those who were not. Nineteen patients required return to the operating room for reintervention during the index hospitalization (10\%), including the 13 with repair thrombosis, one with hematoma, three with flow-limiting stenosis, one with a 
pseduoaneurysm and one with an infection. There was no difference in need for reintervention between patients who underwent ISA and those who did not (9/119 (8\%) vs. 10/74 (14\%), p= 0.2). There were no deaths or hemorrhagic strokes in the total cohort.

\section{DISCUSSION}

Anticoagulation has been investigated as a modifiable risk factor to improve outcomes for patients with extremity arterial injuries. Early use of anticoagulation has been argued to minimize distal and small vessel thrombosis and therefore improve outflow patency $(5,9)$. Despite the dogma for using anticoagulation in vascular repair, in patients undergoing repair of traumatic vascular injuries there is minimal and conflicting data in the literature correlating the use of ISA with improved outcomes. Routine anticoagulation in the absence of contraindications has been recommended by multiple groups $(5,8,9,13)$, but has been found to have no difference by other groups $(4,6,7,10)$. Wagner et al. found a significantly lower amputation rate when ISA was used, in a review of 99 traumatic popliteal artery injuries (8\% vs. 31\%, p < 0.01) (8). They did not, however, account for other confounding patient characteristics like degree of limb ischemia at presentation. Daugherty et al. compared patients with popliteal injuries who received ISA over two sequential five-year periods. Between 1967-1972, 13 patients received ISA with a limb salvage rate of $46 \%$; in contrast to 7 patients who did not receive ISA and had a limb salvage rate of $43 \%$. Between 1972-1977, 11 patients received ISA and the total limb salvage improved to $91 \%$ (5). They also report using improved operative techniques including extra-anatomic bypass in the latter time period, which could account for the difference in outcome. Melton et al. looked at 102 patients with popliteal artery injuries, $79 \%$ of whom were given ISA with or without thrombolysis (7). While there was a trend towards improved limb 
salvage in patients treated with anticoagulation and/or thrombolysis compared to no treatment ( $\mathrm{p}$ $=0.05)$, there was no significant difference in limb salvage in subgroup of 46 patients who were given ISA alone $(\mathrm{p}=0.19)(7)$. Humphries et al. performed a modern retrospective review of 123 patients with extremity injuries, in which $56 \%$ of patients received ISA (6). They found no difference in RTLA with use of ISA (OR 0.74, p = 0.6) (6). Similarly, we found no significant association between ISA and amputation and/or repair thrombosis.

The limb salvage rate observed in this study is consistent with modern studies (9), with 94\% limb salvage. Popliteal artery injuries continue to have the poorest limb salvage rates. There is no appreciable improvement in the overall limb salvage rate of popliteal arteries since the 1980 s; $84 \%$ in this modern study compared to historically reported rates of $83-100 \%(3-5,7$, 8, 13) despite improvements in hospital and pre-hospital care.

The biggest limitation of any database is the detailed information that are not collected. Specifically, data regarding other adjuvant anticoagulation strategies including use of local heparinized-containing irrigation intraoperatively, transexemic acid, dextran, anticoagulation or antiplatelet agents given postoperatively, use of thrombectomy catheters, and details regarding specific ISA dose, pre- or post-administration activated clotting time levels were not collected in the PROOVIT database. These factors could be significant cofounding variables and warrant further investigation.

One main reason anticoagulation is withheld during arterial repair for a trauma patient is the concern for bleeding complications due to concomitant injuries. Anticoagulation given to patients with traumatic arterial injuries without absolute contraindications has been reported to have no increase in the rate of bleeding complications $(5,6,9,10,14)$. Wagner et al. found no 
hemorrhagic complications in the 71 patients given intraoperative systemic anticoagulation (8). Humphries et al. found that use of ISA did not significantly change intraoperative blood loss $(637 \mathrm{~mL}$ vs $926 \mathrm{~mL}, \mathrm{p}=0.23)$ or overall bleeding complications ( $42 \%$ vs $45 \%, \mathrm{p}=0.95)(6)$. Golob et al. found a total complication (major and minor) rate of $21 \%$ in 114 patients given anticoagulation after traumatic injury (15). Our study found significantly higher total PRBC use in patients receiving ISA, as well as longer hospital and ICU stays despite similar ISS, MESS and GCS between the groups. However, the outcomes of thrombosis, amputation, stroke or death were unchanged between the groups. The PROOVIT database does not currently include data regarding specific bleeding complications or strict contraindications for anticoagulation (i.e. intra-cavitary hemorrhage, need for multiple operations), and therefore these potential confounders will be missed.

Though prospectively obtained, this database reflects modern practice only among major Level I academic institutions across the country. Practice patterns of the 5 centers with higher enrollment may dictate some of the trends observed. The database did not collect information on the level of training or specialty of the operating surgeon. This study focused on open arterial repairs, as there were only two identified endovascular repairs undertaken for extremity arterial trauma recorded in the PROOVIT database for this time period. Use and outcomes of endovascular techniques for extremity trauma is being actively explored $(16,17)$, but outcomes associated with these technologies will require additional investigation as experience matures. This preliminary report focuses on in-hospital outcomes following traumatic arterial injury repair, and does not include delayed amputations that may be required long term for limb dysfunction, delayed repair thrombosis or infection. A power calculation determined that to detect a 3\% difference in rate of amputation, 1496 total patients should be analyzed. A more 
robust data set with information on outcomes will be obtained as the PROOVIT database continues to mature.

In this study, anticoagulation given during an operation was not associated with improved

graft patency or limb salvage. Furthermore, ISA use was associated with prolonged hospital stay and increased blood product use. Our data suggest that for traumatic arterial injuries, there is no significant difference in outcome to support use of ISA. Further investigation regarding the risks of ISA for traumatic vascular injuries is needed.

Authorship: This work represents the original efforts of the investigators. All listed authors contributed to study design, data collection, data interpretation, and manuscript development.

Disclosure: The authors declare no conflicts of interest.

\section{Funding Acknowledgement:}

The U.S. Army Medical Research Acquisition Activity, 820 Chandler Street, fort Detrick MD 21702-5014 is the awarding and administering acquisition office. This work was supported by the Office of the Assistant Secretary of Defense for Health Affairs through the Joint Warfighter Medical Research Program under Award No. W81XWH-15-2-0089 through the National Trauma Institute. Opinions, interpretations, conclusions and recommendations are those of the author and are not necessarily endorsed by the Department of Defense. 


\section{REFERENCES}

1. Casale GaP, Iraklis. Ischemia-Reperfusion. In: Cronenwett J, Johnston K, editors. Rutherford's Vascular Surgery. 8th ed. Philadelphia, PA2014.

2. Snyder WH, 3rd. Vascular injuries near the knee: an updated series and overview of the problem. Surgery. 1982;91(5):502-6.

3. Fabian TC, Turkleson ML, Connelly TL, Stone HH. Injury to the popliteal artery. Am J Surg. 1982;143(2):225-8.

4. Hafez HM, Woolgar J, Robbs JV. Lower extremity arterial injury: results of 550 cases and review of risk factors associated with limb loss. J Vasc Surg. 2001;33(6):1212-9.

5. Daugherty ME, Sachatello CR, Ernst CB. Improved treatment of popliteal arterial injuries using anticoagulation and extra-anatomic reconstruction. Arch Surg. 1978;113(11):1317-21.

6. Humphries M, Blume MK, Rodriguez MC, DuBose JJ, Galante JM. Outcomes After Anticoagulation for Traumatic Arterial Injuries of the Extremity. JAMA Surg. 2016.

7. Melton SM, Croce MA, Patton JH, Jr., Pritchard FE, Minard G, Kudsk KA, et al. Popliteal artery trauma. Systemic anticoagulation and intraoperative thrombolysis improves limb salvage. Ann Surg. 1997;225(5):518-27; discussion 27-9.

8. Wagner WH, Calkins ER, Weaver FA, Goodwin JA, Myles RA, Yellin AE. Blunt popliteal artery trauma: one hundred consecutive injuries. J Vasc Surg. 1988;7(5):736-43.

9. Guerrero A, Gibson K, Kralovich KA, Pipinos I, Agnostopolous P, Carter Y, et al. Limb loss following lower extremity arterial trauma: what can be done proactively? Injury. 2002;33(9):765-9. 
10. Fabian TC, Patton JH, Jr., Croce MA, Minard G, Kudsk KA, Pritchard FE. Blunt carotid injury. Importance of early diagnosis and anticoagulant therapy. Ann Surg. 1996;223(5):513-22; discussion 22-5.

11. DuBose JJ, Savage SA, Fabian TC, Menaker J, Scalea T, Holcomb JB, et al. The American Association for the Surgery of Trauma PROspective Observational Vascular Injury Treatment (PROOVIT) registry: multicenter data on modern vascular injury diagnosis, management, and outcomes. J Trauma Acute Care Surg. 2015;78(2):215-22; discussion 22-3.

12. Johansen K, Daines M, Howey T, Helfet D, Hansen ST, Jr. Objective criteria accurately predict amputation following lower extremity trauma. J Trauma. 1990;30(5):568-72; discussion $72-3$.

13. Lim LT, Michuda MS, Flanigan DP, Pankovich A. Popliteal artery trauma. 31 consecutive cases without amputation. Arch Surg. 1980;115(11):1307-13.

14. Cothren CC, Moore EE, Biffl WL, Ciesla DJ, Ray CE, Jr., Johnson JL, et al. Anticoagulation is the gold standard therapy for blunt carotid injuries to reduce stroke rate. Arch Surg. 2004;139(5):540-5; discussion 5-6.

15. Golob JF, Jr., Sando MJ, Kan JC, Yowler CJ, Malangoni MA, Claridge JA. Therapeutic anticoagulation in the trauma patient: is it safe? Surgery. 2008;144(4):591-6; discussion 6-7.

16. Desai SS, DuBose JJ, Parham CS, Charlton-Ouw KM, Valdes J, Estrera AL, et al.

Outcomes after endovascular repair of arterial trauma. J Vasc Surg. 2014;60(5):1309-14.

17. Kufner S, Cassese S, Groha P, Byrne RA, Schunkert H, Kastrati A, et al. Covered stents for endovascular repair of iatrogenic injuries of iliac and femoral arteries. Cardiovasc Revasc Med. 2015;16(3):156-62. 
Table 1: Demographics of included patients, analyzed by intraoperative anticoagulation status.

\begin{tabular}{|c|c|c|c|c|}
\hline \multirow[b]{2}{*}{ Factor } & \multirow[b]{2}{*}{ All } & \multicolumn{2}{|c|}{$\begin{array}{c}\text { Intraoperative Systemic } \\
\text { Anticoagulation }\end{array}$} & \multirow[b]{2}{*}{ p-value } \\
\hline & & Received & Not Received & \\
\hline Mean age $(\mathrm{SD})$ & $32.6(15.3)$ & $32.2(15.1)$ & $33.4(15.7)$ & $0.6^{*}$ \\
\hline Male, n (\%) & $167 / 193(87)$ & $109 / 119(92)$ & $58 / 74(78)$ & $0.02 \dagger$ \\
\hline Injury mechanism & & & & $0.5^{\dagger}$ \\
\hline Blunt, n (\%) & $47 / 193(24)$ & $32 / 119(27)$ & $15 / 74(20)$ & \\
\hline Penetrating, n (\%) & $142 / 193(74)$ & $85 / 119(71)$ & $57 / 74(77)$ & \\
\hline Mixed blunt and penetrating, n (\%) & $4 / 193(2)$ & $2 / 119(2)$ & $2 / 74(3)$ & \\
\hline Specific mechanism & & & & $0.5^{\dagger}$ \\
\hline Gunshot, n (\%) & $80 / 193(42)$ & $53 / 119(45)$ & 27/74 (37) & \\
\hline Stabbing, n (\%) & $29 / 193(15)$ & $16 / 119(13)$ & $13 / 74(18)$ & \\
\hline Motor Vehicle Collision, n (\%) & 25/193 (13) & $17 / 119(14)$ & $8 / 74(11)$ & \\
\hline Other, n (\%) & $59 / 193(31)$ & $33 / 119(28)$ & $26 / 74(35)$ & \\
\hline Injury description & & & & $0.5^{\dagger}$ \\
\hline Flow limiting defect, $\mathrm{n}(\%)$ & $33 / 193(17)$ & $22 / 119(19)$ & $11 / 74(15)$ & \\
\hline Occlusion, n (\%) & $24 / 193(12)$ & $18 / 119(15)$ & $6 / 74(8)$ & \\
\hline Pseudoaneurysm, n (\%) & $6 / 193(3)$ & $3 / 119(3)$ & $3 / 74(4)$ & \\
\hline Transection, $\mathrm{n}(\%)$ & $121 / 193(63)$ & $71 / 119(60)$ & $50 / 74(68)$ & \\
\hline Other injury type, n (\%) & $9 / 193(5)$ & $5 / 119(4)$ & $4 / 74(5)$ & \\
\hline Median ISS (Q1, Q3) & $9(9,16)$ & $10(9,16)$ & $9(5,16)$ & $0.1 \S$ \\
\hline Mean admission SBP (SD) & $120.9(28.5)$ & $120.5(29.8)$ & $121.6(26.6)$ & $0.8^{*}$ \\
\hline Median GCS (Q1, Q3) & $15(15,15)$ & $15(15,15)$ & $15(15,15)$ & $0.7 \S$ \\
\hline Median AIS-extremity (Q1, Q3) & $3(3,3)$ & $3(3,3)$ & $3(2,3)$ & $0.06 \S$ \\
\hline Median MESS (Q1, Q3) & $4(3,6)$ & $4(3,6)$ & $4(3,5)$ & $0.08^{\S}$ \\
\hline Median Skeletal / Soft tissue Score (Q1, Q3) & $1(1,2)$ & $1(1,2)$ & $1(1,1)$ & $0.1 \S$ \\
\hline Median Limb Ischemia Score (Q1, Q3) & $1(1,2)$ & $2(1,2)$ & $1(1,1)$ & $<0.001^{\S}$ \\
\hline Median Shock Score (Q1, Q3) & $0(0,1)$ & $0(0,1)$ & $0(0,1)$ & $0.9 \S$ \\
\hline Median Age Score (Q1, Q3) & $0(0,1)$ & $0(0,1)$ & $1(0,1)$ & $0.3^{\S}$ \\
\hline Concomitant vein injury, $\mathrm{n}(\%)$ & $71 / 193(37)$ & $44 / 119(37)$ & $27 / 74(37)$ & $0.9 \ddagger$ \\
\hline Vein repaired, n $(\%)$ & $63 / 71(89)$ & $40 / 44(91)$ & $23 / 27(85)$ & $0.7 \ddagger$ \\
\hline Concomitant nerve injury, $\mathrm{n}(\%)$ & $63 / 193(33)$ & $31 / 119(26)$ & $32 / 74(43)$ & $0.02 \ddagger$ \\
\hline Concomitant orthopedic injury, n (\%) & $66 / 193(34)$ & $43 / 119(36)$ & $23 / 74(31)$ & $0.6^{\ddagger}$ \\
\hline
\end{tabular}

* Two-tailed t-test

† Pearson's Chi-square

₹ Chi-square with Yates’ continuity correction

$\S$ Wilcoxon Rank-Sum

ISS = Injury severity score

AIS $=$ Abbreviated injury score
SBP $=$ Systolic blood pressure

GCS = Glasgow coma score

MESS = Mangled extremity severity score

$\mathrm{SD}=$ standard deviation

$\mathrm{Q} 1=$ Lower quantile $\left(25^{\text {th }}\right.$ percentile $)$

$\mathrm{Q} 3=$ Upper quantile $\left(75^{\text {th }}\right.$ percentile 
Table 2: Management of injuries, analyzed by intraoperative anticoagulation status.

\begin{tabular}{|c|c|c|c|c|}
\hline \multirow[b]{2}{*}{ Factor } & \multirow[b]{2}{*}{ All } & \multicolumn{2}{|c|}{$\begin{array}{c}\text { Intraoperative Systemic } \\
\text { Anticoagulation }\end{array}$} & \multirow[b]{2}{*}{ p-value } \\
\hline & & Received & $\begin{array}{c}\text { Not } \\
\text { Received }\end{array}$ & \\
\hline Pre-hospital Tourniquet, n (\%) & $43 / 193(22)$ & $24 / 119(20)$ & $19 / 74(26)$ & 0.4 \\
\hline Time from Injury to Repair & & & & $0.4^{\dagger}$ \\
\hline Less than 3 hours, $\mathrm{n}(\%)$ & $41 / 193(21)$ & $23 / 119(19)$ & $18 / 74(24)$ & \\
\hline $3-6$ hours, $n(\%)$ & $104 / 193(54)$ & $71 / 119(60)$ & $33 / 74(45)$ & \\
\hline Greater than 6 hours, $\mathrm{n}(\%)$ & $33 / 193(17)$ & 20/119 (17) & $13 / 74(18)$ & \\
\hline Temporary shunt utilized, n (\%) & 9/193 (5) & $8 / 119(7)$ & $1 / 74(1)$ & 0.2 \\
\hline Repair Method & & & & $0.001^{\dagger}$ \\
\hline Autologous repair, n (\%) & $103 / 193(53)$ & $74 / 119(62)$ & $29 / 74(39)$ & \\
\hline Primary repair, n $(\%)$ & $81 / 193(42)$ & $38 / 119(32)$ & $43 / 74(58)$ & \\
\hline Synthetic graft utilization, n (\%) & $8 / 193(4)$ & $7 / 119(6)$ & $1 / 74(1)$ & \\
\hline Immediate revision required intraoperatively, $\mathrm{n}(\%)$ & $28 / 193(15)$ & $20 / 119(17)$ & $8 / 74(11)$ & 0.3 \\
\hline Fasciotomy, n (\%) & $78 / 193(40)$ & $57 / 119(48)$ & $21 / 74(28)$ & $0.01 \ddagger$ \\
\hline Intraoperative time & & & & $0.04^{\dagger}$ \\
\hline Less than 3 hours, n (\%) & $78 / 193(40)$ & $42 / 119(35)$ & $36 / 74(49)$ & \\
\hline $3-6$ hours, n $(\%)$ & $84 / 193(44)$ & $60 / 119(50)$ & $24 / 74(32)$ & \\
\hline Greater than 6 hours, $\mathrm{n}(\%)$ & $16 / 193(8)$ & $12 / 119(10)$ & $4 / 74(5)$ & \\
\hline
\end{tabular}

† Pearson's Chi-square

₹ Chi-square with Yates' continuity correction 1-tailed Fisher's exact test, doubled 
Table 3: Analysis of intraoperative anticoagulation status and outcome, by artery injured.

\begin{tabular}{|c|c|c|c|c|c|c|}
\hline & & & \multicolumn{2}{|c|}{ Amputations } & \multicolumn{2}{|c|}{ RTLA } \\
\hline Artery Injured & $\begin{array}{c}\text { Total } \\
\text { Injuries }\end{array}$ & $\begin{array}{c}\text { ISA } \\
\text { Received }\end{array}$ & $\begin{array}{c}\text { ISA } \\
\text { Received }\end{array}$ & $\begin{array}{c}\text { ISA Not } \\
\text { Received }\end{array}$ & $\begin{array}{c}\text { ISA } \\
\text { Received }\end{array}$ & $\begin{array}{c}\text { ISA Not } \\
\text { Received }\end{array}$ \\
\hline Brachial artery, n (\%) & $47 / 193(24)$ & $32 / 47(68)$ & $0 / 32(0)$ & $0 / 15(0)$ & $3 / 32(9)$ & $2 / 15(13)$ \\
\hline Forearm arteries, n (\%) & $49 / 193(25)$ & $19 / 49(39)$ & $1 / 19(5)$ & $0 / 30(0)$ & $1 / 19(5)$ & $1 / 30(3)$ \\
\hline Femoral artery, n (\%) & $58 / 193(30)$ & $39 / 58(67)$ & $2 / 39(5)$ & $2 / 19(11)$ & $4 / 39(10)$ & $3 / 19(16)$ \\
\hline Popliteal artery, n (\%) & $31 / 193(16)$ & $26 / 31(84)$ & $4 / 26(15)$ & $1 / 5(20)$ & $4 / 26(15)$ & $3 / 5(60)$ \\
\hline Distal to popliteal, n (\%) & $8 / 193(4)$ & $3 / 8(38)$ & $0 / 3(0)$ & $1 / 5(20)$ & $0 / 3(0)$ & $1 / 5(20)$ \\
\hline
\end{tabular}

RTLA = Repair thrombosis and / or amputation

ISA $=$ intraoperative systemic anticoagulation 
Table 4: Outcomes after repair, analyzed by intraoperative anticoagulation status.

\begin{tabular}{|c|c|c|c|c|}
\hline \multirow[b]{2}{*}{ Outcome } & \multirow[b]{2}{*}{ Total } & \multicolumn{2}{|c|}{$\begin{array}{c}\text { Intraoperative systemic } \\
\text { anticoagulation }\end{array}$} & \multirow[b]{2}{*}{ p-value } \\
\hline & & Received & Not received & \\
\hline Median total units PRBC (Q1, Q3) & $2(0,6)$ & $3(0,8)$ & $1(0,4)$ & $0.002^{\S}$ \\
\hline Median days of ICU stay (Q1, Q3) & $2(0,5)$ & $3(1,6)$ & $1(0,3)$ & $0.001^{\S}$ \\
\hline Median days of total hospital stay (Q1, Q3) & $8(3,17)$ & $9.5(4,18.5)$ & $6(2,13)$ & $0.01^{\S}$ \\
\hline Re-intervention required after repair, n (\%) & $19 / 193(10)$ & $9 / 119(8)$ & $10 / 74(14)$ & 0.2 \\
\hline Composite endpoint RTLA, n (\%) & $22 / 193(11)$ & $12 / 119(10)$ & $10 / 74(14)$ & 0.6 \\
\hline Amputation, $\mathrm{n}(\%)$ & $11 / 193(6)$ & $7 / 119(6)$ & $4 / 74(5)$ & 1.0 \\
\hline Thrombosis, n (\%) & $13 / 193(7)$ & $6 / 119(5)$ & $7 / 74(10)$ & 0.4 \\
\hline
\end{tabular}

$\S$ Wilcoxon Rank-Sum

1-tailed Fisher's exact test, doubled

RTLA = Repair thrombosis and / or amputation

PRBC $=$ Packed red blood cells

ICU = intensive care unit

$\mathrm{Q} 1=$ Lower quantile $\left(25^{\text {th }}\right.$ percentile $)$

$\mathrm{Q} 3=$ Upper quantile $\left(75^{\text {th }}\right.$ percentile $)$ 